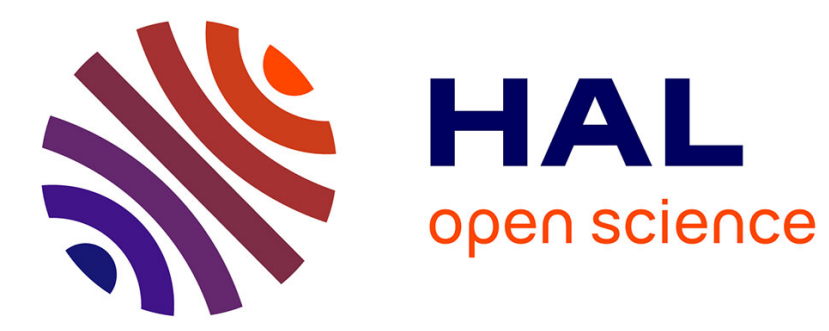

\title{
Consistent experimental investigation of the applicability of Biot-Gassmann's equation in carbonates
}

\author{
Elisabeth Bemer, Youri Hamon, Mathilde Adelinet
}

\section{To cite this version:}

Elisabeth Bemer, Youri Hamon, Mathilde Adelinet. Consistent experimental investigation of the applicability of Biot-Gassmann's equation in carbonates. Geophysics, 2019, 84 (4), pp.WA97-WA113. 10.1190/geo2018-0631.1. hal-02299332

\section{HAL Id: hal-02299332 \\ https://hal-ifp.archives-ouvertes.fr/hal-02299332}

Submitted on 27 Sep 2019

HAL is a multi-disciplinary open access archive for the deposit and dissemination of scientific research documents, whether they are published or not. The documents may come from teaching and research institutions in France or abroad, or from public or private research centers.
L'archive ouverte pluridisciplinaire HAL, est destinée au dépôt et à la diffusion de documents scientifiques de niveau recherche, publiés ou non, émanant des établissements d'enseignement et de recherche français ou étrangers, des laboratoires publics ou privés. 


\title{
CONSISTENT EXPERIMENTAL INVESTIGATION OF THE APPLICABILITY OF BIOT- GASSMANN'S EQUATION IN CARBONATES
}

\begin{abstract}
Carbonate formations are characterized by multiscale heterogeneities which control their flow and acoustic responses. At the laboratory scale, carbonate rocks already do not show a strong correlation between P- and S-wave velocities and porosity. The velocity disparities between carbonates of similar mineralogy and porosity result from different microstructures derived from their sedimentary facies and subsequent diagenetic transformations. The still discussed applicability of Biot-Gassmann's equation for fluid substitution in carbonate rocks remains another key issue. We propose an integrated experimental workflow that allows a consistent checking of the applicability of Biot-Gassmann's equation and provide key geological and microstructural information to understand the petroacoustic signature of carbonate rocks. This approach is implemented on samples representative of two different carbonate formations. The obtained results demonstrate the applicability of Biot-Gassmann's equation for the two studied carbonate families and show the interrelation of mineralogy and porosity distribution in their acoustic response.
\end{abstract}

\section{INTRODUCTION}

Evaluating carbonate formations is of paramount importance as they hold a large part of the world's hydrocarbon reserves (Dennis et al., 2003) and some key groundwater resources (Green et al., 2014). They are moreover considered as potential hosts for $\mathrm{CO}_{2}$ storage (Brosse et 
al., 2010; Bemer et al., 2016). Carbonate rocks are characterized by multiscale heterogeneities which control their flow and acoustic responses. Understanding the distribution of heterogeneities in carbonate sedimentary systems represents a major challenge for the characterization and modeling of carbonate formations. Addressing this key issue notably requires taking into account both initial sedimentary processes and further diagenetic modifications. Another key step is to correlate geological data with petrophysical and petroacoustic properties that can be used to define models populated with geologically consistent rock types thus improving the reliability of flow modeling and 4D seismic monitoring.

At the laboratory scale, carbonate rocks already do not show a strong correlation between P- and S-wave velocities and porosity (Anselmetti and Eberli, 1993; Kenter et al., 1997a; Assefa et al., 2003; Verwer et al., 2008; Weger et al., 2009; Fabricius et al., 2010), which prevents a straight interpretation of acoustic data in terms of reservoir petrophysical characteristics. In addition to porosity and mineralogy, the main controlling factors are related to the pore types. Carbonates dominated by pores with high aspect ratios usually show higher velocities than carbonates dominated by pores with low aspects ratios (Assefa et al., 2003; Baechle et al., 2005). Better velocity trends as a function of porosity have been obtained by Baechle et al. (2008) when considering microporosity instead of total porosity. Based on their extensive dataset, Weger et al. (2009) have concluded that microporous samples with small pores and high specific surface show lower velocity than samples with large pores and low specific surface. Those two end members could however be affected by specific measurement artifacts which were not considered by the authors. Carbonates with high specific surface could be susceptible to water weakening leading to lower velocities for water-saturated samples (Baechle et al., 2005; Adam et 
al., 2006; Verwer et al., 2010), while large pores could induce acoustic scattering leading to overestimated velocities (Cadoret et al., 1995; Rasolofosaon and Zinszner, 2012).

The velocity disparities between carbonates of similar mineralogy and porosity can more generally be related to different microstructures resulting from the combination of their sedimentary facies and subsequent diagenetic transformations (Kenter et al., 1997b; Eberli et al., 2003; Verwer et al., 2008). The understanding of the petroacoustic signature of carbonate rocks will thus require an insight into the impact of diagenesis on acoustic velocities (Brigaud, 2010; Regnet et al., 2015; Matonti et al., 2015).

The still discussed applicability of Biot-Gassmann's equation for fluid substitution in carbonate rocks remains another key issue (Adam and Batzle, 2008; Raoslofosaon et al., 2008; Fabricius et al., 2010; Rasolofosaon and Zinszner, 2012). In addition to the abovementioned scattering and weakening effects, the reported deviations are linked to dispersion and more prosaically the assessment of the input parameters (Han and Batzle, 2004; Yan and Han, 2016).

The objective of our work is to derive an integrated experimental workflow designed to allow a consistent checking of the applicability of Biot-Gassmann's equation and provide key geological and microstructural information for an effective medium modeling approach presented in a companion paper (Adelinet et al., 2018). We first present the specific test sequence which includes petrographic analysis, petrophysical and petroacoustic testing and microstructure analyses. Each experimental method is detailed with a specific focus on the key contribution of the petroacoustic methodology and on the different nature of the information provided by the microstructure analyses. The petrophysical properties and microstructure characteristics of two sets of carbonate samples are then presented. The petroacoustic results are 
then carefully interpreted to demonstrate the applicability of Biot-Gassmann's equation for the two carbonate families without any assumptions on the input parameters. We finally discuss the limitations of Biot-Gassmann's equation for the modeling of the petroacoustic signature of carbonate rocks.

\section{METHODS}

\section{Experimental characterization workflow}

A specific experimental workflow has been designed to provide a comprehensive dataset including both input and constraining data for effective medium modeling. The samples are first observed under CT-scanner to check their heterogeneity level and select the most homogeneous part for the characterization process. The workflow includes a non-destructive testing sequence performed on the main sample and a series of microstructure analyses performed on subsamples (Figure 1). The successive non-destructive characterization steps are: petroacoustic testing, porosity measurement, NMR analysis on the brine-saturated sample and brine permeability measurement. The main sample is then cut into several subsamples to obtain a vertical thin section, powder for XRD analysis and small parts for mercury injection and possibly microscanner imaging. This last analysis being costly, it is not performed on the whole sample set.

\section{Petrophysical and petroacoutic characterization}

Petrophysical measurements 
The porosity of the samples has been estimated from the difference between their brinesaturated and dry weights. These measurements are performed using $25 \mathrm{~g} / 1 \mathrm{NaCl}$ brine. The brine-saturated state is obtained after saturation within the petroacoustic cell. The sample is then dried in an oven at $60^{\circ} \mathrm{C}$ to measure its dry weight. Knowing the bulk volume of the sample and the brine density, the porosity $\phi_{W e i g h t}$ is finally deduced. Another porosity estimation $\phi_{N M R}$ has been deduced from the pore volume provided by the NMR analysis.

Permeability measurements are performed in a Hassler cell using $25 \mathrm{~g} / \mathrm{l} \mathrm{NaCl}$ brine. After setting the brine-saturated sample inside the cell, several flow rates are applied at the inlet while the outlet is kept at a constant pressure. Each flow rate $Q$ is maintained until equilibration of the differential pressure $\Delta p_{p}$. The intrinsic permeability $k$ is then simply deduced from the slope of the $Q-\Delta p_{p}$ curve using Darcy's law:

$$
k=\eta^{\text {brine }} \frac{h}{S} \frac{d Q}{d \Delta p_{p}}
$$

where $\eta^{\text {brine }}$ is the brine dynamic viscosity, $h$ the sample length and $S$ its section. At least four flow rates are applied for each permeability measurement.

\section{Petroacoustic measurements}

The acoustic experimental device is designed to perform velocity measurements along the sample axis under controlled isotropic confining pressure (up to $70 \mathrm{MPa}$ ) and pore pressure (up to $10 \mathrm{MPa}$ ) using double $\mathrm{P}$ and $\mathrm{S}$ transducers (half-moon ceramic) with a central frequency of $500 \mathrm{kHz}$. The experiments are performed at a differential pressure (confining pressure minus pore pressure) representative of in situ conditions. 
To probe the acoustic response of the samples to a fluid change we use the fluid substitution method proposed by Rasolofosaon and Zinszner (2003, 2012). This approach consists in subsequently measuring the acoustic velocities for various saturating liquids of different bulk modulus, the current saturating fluid being replaced with a miscible one to ensure successive fully saturated states. The key contribution of fluid substitution tests is to allow a direct checking of the validity of Biot-Gassmann's equation without referring to less-controlled dry measurements (Rasolofosaon and Zinszner, 2003). The physical properties of the different fluids used are given in Table 1: the bulk modulus of each fluid has been measured using a pair of P-type piezoelectric ceramics set at a fixed distance and immersed into the fluid at the pressure applied during the petroacoustic tests (i.e. 1.5 MPa); the density and viscosity values correspond to standard fluid properties at $20^{\circ} \mathrm{C}$. We have shown that this set of fluids covers a sufficiently large range of bulk modulus to allow a consistent checking of Biot-Gassmann's equation for an outcrop limestone (Bemer et al., 2016). The bulk moduli of methanol and ethanol are very close; the intermediate flushing by methanol is intended to ease the fully miscible replacement of the more viscous ethylene glycol and provide a control point. After the saturation with heptane, the sample is again flushed by ethanol then brine to take the sample out of the petroacoustic cell in a brine-saturated state allowing its direct analysis in the NMR device. The fluid sequence is then the following: brine $(25 \mathrm{~g} / \mathrm{l} \mathrm{NaCl})$, ethylene glycol, methanol, ethanol, heptane, ethanol, brine $(25 \mathrm{~g} / 1 \mathrm{NaCl})$.

The ultrasonic signals are analyzed using two different approaches: the first break picking, which gives the impetus velocity, and the phase spectral ratio method, which gives the phase velocity. This second method consists in applying a Fourier transform to the recorded signal and comparing it, in the frequency domain, with a reference signal recorded in a 
homogeneous medium of perfectly known velocity (in this case an aluminum sample). Further details on this method can be found in Bemer et al. (2016). All the velocity computations have been performed using an in-house LabView software and considering one and a half signal period for the phase velocity. Each measurement of $\mathrm{P}$ and $\mathrm{S}$ velocities has been repeated three times with deviations below $1 \%$ and $0.5 \%$ respectively for first break and phase velocities. The first break velocity is directly impacted by the transmitted wave form which can complicate the picking of the arrival time especially for the $S$ wave due to the noise associated with the preceding weak P signal. An additional 1\% error has been considered for the first break velocities to account for the picking uncertainty. Two specific uncertainty sources have been considered for phase velocities: the impact of the signal window used for the computation and the possible influence of the reference signal. Reference samples of different lengths have notably been used with an induced deviation below $1 \%$. The maximum errors on both first break and phase velocity measurements are finally considered as less than $2 \%$.

Carbonate heterogeneity is known to induce scattering effects usually referred to as "path dispersion" (Cadoret et al., 1995). Contrary to the first break picking which may measure the travel time corresponding to fastest paths taken by part of the acoustic energy and thus lead to overestimated acoustic velocities, the computation of the phase velocity minimizes the effect of heterogeneity. The measured phase velocities are then more representative of the sample macroscopic behavior (Cadoret et al., 1995; Rasolofosaon and Zinszner, 2012; Bemer et al., 2016).

\section{Microstructure characterization}


Effective medium modeling relies on the definition of representative microstructure models and thus on a comprehensive characterization of the microstructure of the studied samples. Table 2 lists the various methods combined to gather microstructure information. The emphasis is notably laid on the nature of the information and the limitations associated with each approach. The petrographic analysis and the derived paragenesis are described in our companion paper (Adelinet et al., 2018).

\section{Microscanner imaging}

Sub-samples are cored from the portion remaining after cutting off the vertical thin section. The 8-mm diameter of the sub-samples results from a compromise between the representativeness with regard to the original sample and the resolution of the acquisition. The sub-samples are dried for $48 \mathrm{~h}$ at $60^{\circ} \mathrm{C}$ to remove residual water and then imaged using the phoenix nanotom ${ }^{\circledR}$ computed tomography system. In a second step, the samples are vacuumed and fully saturated with $40 \mathrm{~g} / \mathrm{l} \mathrm{KI}$ brine within a cell pressurized at $10 \mathrm{MPa}$ for $24 \mathrm{~h}$ to dissolve any residual gas. The sub-samples are then sealed to avoid subsequent drying and imaged using the same acquisition conditions than for the dry state. The sample areas invaded by the brine are then be derived from the difference between the brine-saturated image and the dry one (Figure 2).

For all the samples, the phoenix nanotom ${ }^{\circledR}$ computed tomography system has been set to work at $90 \mathrm{keV}$ and $170 \mu \mathrm{A}$. The magnification is $12.5 \times$ resulting in a voxel size of $4 \mu \mathrm{m}$. A sub-volume of $900 \times 900 \times 800$ voxels is then reconstructed with a voxel binning of two and a 16-bit grey level depth. This results in a 3D image with a voxel size of $8 \mu \mathrm{m}$ and a diameter of $7.2 \mathrm{~mm}$. 
The noise inherent to computed micro-tomography reconstruction can complicate the direct identification of the grey level associated to each phase. To enhance the local contrast between the different constituents of the images while keeping a sufficiently large grey level histogram, a mean filtering is applied to the 16-bit images. It consists in affecting to a given voxel the mean grey level value of a kernel of $5^{3}$ neighboring voxels. This procedure notably limits blurring effects at the interface between the different phases of the studied volume.

The differences in grey levels between the KI-saturated and dry samples are only due to the invasion of the porosity by the KI brine, the grey levels of the solid phases remaining unchanged. The grey levels being proportional to the density, the total porosity $\phi_{C T}$ is deduced from the mean grey level of the 3D images obtained for the dry and KI-saturated samples, $\mathrm{G}_{d r y}$ and $\mathrm{G}_{\text {sat }}$ :

$$
\phi_{C T}=\frac{G_{s a t}-G_{d r y}}{g_{K I}-g_{v o i d}}
$$

where $g_{v o i d}$ is the grey level of the void phase and $g_{K I}$ the grey level of the KI-brine. The grey values characterizing the voids and the KI brine have been determined from the sample showing the larger macropores (F1-13) and then used for all samples.

The microporosity of the samples is simply deduced from the difference between the obtained total porosity and the resolved macroporosity. However it is not possible to determine the mineral composition of the microporous phase through grey level histogram partitioning.

\author{
X-Ray Diffraction (XRD)
}


The sample pieces intended for XRD analysis are ground to an appropriate size (around 20-30 $\mu \mathrm{m})$ and mixed with alumina (20\% of the analyzed mass) for proper mineral quantification. The data are then interpreted to compute volume fractions from the weight contents classically provided by the XRD analysis.

The method is the following: identification of the minerals from the diffraction lines; numerical simulation of the diffraction profiles using the Rietvield method (Rietvield, 1969); computation of the specific density of the identified minerals using the information on crystal structures provided by the simulation process; computation of volume fractions from weight contents and specific densities. The computed specific densities are systematically compared to the values expected for the identified minerals as a quality check.

Nuclear Magnetic Resonance (NMR)

NMR analysis is performed on the brine-saturated samples. In addition to the pore volume, NMR experiments measure a magnetization decay curve $M(t)$ at a regular time interval (e.g. $100 \mu \mathrm{s}$ ). This curve is then usually analyzed as a sum of exponential decays:

$$
M(t)=\sum_{i} A_{i} \exp \left(-\frac{t}{T_{2 i}}\right)
$$

The distribution of relaxation times is a plot of the amplitudes $A_{i}$ as a function of $T_{2 i}$. The magnetization $M(t)$ cannot be measured at $t=0$ but at a time depending on the instrument capabilities. This time defines the detection limit which was equal to $0.1 \mathrm{~ms}$ for the studied 38mm diameter samples. In the fast diffusion regime, each $T_{2}$ component is linked to the volume to surface ratio of a pore according to: 
Geophysics

$$
\frac{1}{T_{2}}=\frac{1}{T_{2 b}}+\rho_{2} \frac{S_{\text {pore }}}{V_{\text {pore }}}
$$

where $T_{2 b}$ is the bulk relaxation time of the saturating fluid, $\rho_{2}$ is the surface relaxivity, $S_{\text {pore }}$ is the pore surface and $V_{\text {pore }}$ the pore volume. $T_{2 b}$ defines the upper limit of relaxation time distributions. Hence, the $T_{2}$ distribution, which is often called pore size distribution, actually reflects a distribution of $V_{\text {pore }} / S_{\text {pore }}$ and thus includes a shape factor as well as the surface rugosity.

For samples showing large pores having relaxation times approaching $T_{2 b}$, one should subtract $T_{2 b}$ which is no longer negligible (Vincent et al., 2011). This is performed in the time domain according to:

$$
M(t) / \exp \left(-\frac{t}{T_{2 b}}\right)=\sum_{i} A_{C i} \exp \left(-\frac{t}{T_{2 i}}\right)
$$

All the distributions presented in this paper have been computed according to equation (5) with $T_{2 b}=2700 \mathrm{~ms}$.

A key assumption in the computation of the NMR pore size distribution is that there is no pore coupling effect, which means that the molecules from a given compartment are not mixed through diffusion process with other molecules from nearby compartments (Fleury et al., 2009). When no pore coupling is observed, a comparative study between NMR and MICP data obtained on carefully selected carbonate samples of various origins has shown that a cut-off of $200 \mathrm{~ms}$ in the NMR $T_{2}$ distribution is suitable for separating the microporosity from the macroporosity, in 
accordance with a pore throat diameter cut-off of $2 \mu \mathrm{m}$ for MICP distributions (Vincent et al., 2011).

Mercury Injection Capillary Pressure (MICP)

MICP experiments measure the volume of mercury penetrating the rock sample for a given pressure increment. The pore throat diameter $d_{H g}$ associated to a given mercury invasion pressure $p_{H g}$ is deduced from Laplace's law. The invasion pressure is increased up to $400 \mathrm{MPa}$, corresponding to throat diameters down to $3.6 \mathrm{~nm}$. The sample pore volume is deduced from the cumulative injected volume and used to compute the mercury saturation $S_{H g}$.

As recommended by Lenormand (2003) and Vincent et al. (2011), the pore size distribution is deduced from the following dimensionless equation:

$$
g\left(d_{H g}\right)=p_{H g} \frac{d S_{H g}}{d p_{H g}}
$$

The MICP derived pore size distribution only reflects the volume accessible through the pore throats at a given pressure. The microporosity fraction determined through a $2 \mu \mathrm{m}$ cut-off can then be overestimated if the connectivity of the porous structure is such that large pores are accessible only through small pores with small throats.

\section{PETROPHYSICAL PROPERTIES AND MICROSTRUCTURE CHARACTERISTICS}

Two sets of carbonate samples, designated hereafter as Family 1 (F1) and Family 2 (F2), have been studied. Table 3 gives the measured petrophysical properties. Sample set 1 includes 5 samples with porosity values ranging from 13 to $22 \%$ and permeability values between 100 and 
$400 \mathrm{mD}$. Sample set 2 includes 6 samples with porosity values ranging from 6 to $22 \%$ and permeability values between 0.1 and $6 \mathrm{mD}$. The higher $\phi_{N M R}$ values are due to brine remaining within the samples after drying. This systematic deviation remains below one porosity unit (1\%) for all the samples except for sample F1-13 which showed a deviation above two porosity units (2\%). A second NMR analysis performed on this specific samples after drying has confirmed the presence of residual brine accounting for the deviation between $\phi_{N M R}$ than $\phi_{W e i g h t}$.

Discrepancies between $\phi_{N M R}$ and $\phi_{W e i g h t}$ and the porosity values deduced from microscanner and MICP analysis could be related to the smaller volumes investigated by these methods.

The main phases identified from the XRD analysis are consistent with thin section analysis (Adelinet et al., 2018) and consist in calcite, dolomite and silicate, this last phase grouping quartz and a small fraction of feldspars. Other scarce phases such as clay minerals are neglected. The volume fractions provided in Table 4 are normalized to ensure a sum of 1 mandatory for effective medium modeling.

With the exception of sample F2-2, the two rock families show similar porosity ranges and differ mainly by their permeability levels and their mineral contents. The samples from Family 2 are characterized by significantly higher dolomite contents and lower permeability values. Sample F2-2 has been selected to extend the porosity range of Family 2. However, this sample shows a calcite content of more than $40 \%$, whereas the other F2 samples are characterized by calcite contents below $10 \%$.

F2 samples are expected to display higher microporosity fractions due to their lower permeability. This is confirmed by NMR, MICP and microscanner analyses (Table 5). As stated above, these three methods explore different physical parameters: NMR $T_{2}$ distributions are 
related to the pore volume over surface ratios; MICP distributions give information on the pore throat sizes and microscanner imaging allows the identification of the volume fraction occupied by pores larger than $8 \times 8 \times 8 \mu^{3}$. The information provided by microscanner imaging is the more physically consistent for effective medium modeling. It is however not available for all the samples and has been obtained on a volume smaller than the one investigated by NMR analysis.

Figure 3 compares the NMR and MICP distributions for F1 and F2 samples. All distributions have been normalized to facilitate comparison. Some discrepancies in the shape of the NMR and MICP distributions are observed for F1 samples. The more porous samples, F1-15, F1-17 and F1-21, show similar main modes for both sets of distributions (around 350 ms for the NMR $T_{2}$ mode and $2 \mu \mathrm{m}$ for the MICP pore-throat size mode). The microporosity fractions associated to $T_{2}$ below $200 \mathrm{~ms}$ and pore-throat diameter below $2 \mu \mathrm{m}$ are consistent with each other and with the additional estimation provided by microscanner analysis for sample F1-21 (Table 5). The MICP distributions of samples F1-12 and F1-13 show a dominant contribution of macropores and thus give lower microporosity fractions. The NMR microporosity fraction of sample F1-12 is consistent with the value deduced from microscanner analysis and thus considered as more reliable than the MICP estimation. In the case of sample F1-13, a strong coupling effect is suspected due to the low value of the NMR $T_{2}$ mode (below $200 \mathrm{~ms}$ ). The microporosity fraction deduced from microscanner imaging should then be the most representative estimation.

The shape of the NMR and MICP distributions for F2 samples are consistent. The microporosity fractions derived from MICP analysis are however systematically lower than the NMR microporosity fractions which are closer to the microscanner data and thus deemed more 
reliable. A closer analysis of the initial CT-scanner image of the original sample shows that subsample F2-3 has unfortunately been taken from an area showing few macropores which explains the computed high microporosity fraction and illustrates the specific issue of heterogeneity for carbonate rocks.

Finally, except for sample F1-13, the representative microporosity fractions correspond to the NMR information.

\section{PETROACOUSTIC SIGNATURE OF FLUID SUBSTITUTION: VALIDITY OF BIOT- GASSMANN'S EQUATION}

Biot-Gassmann's equation is widely used to model fluid effects on acoustic properties (Mavko et al., 1998). The poromechanical framework underlying this equation is detailed in Bemer et al. (20016). The key assumptions are: a) quasistatic perturbations; b) homogeneous porous medium with a solid frame exhibiting an isotropic linear elastic behavior; c) homogeneous solid matrix exhibiting an isotropic linear elastic behavior; d) considered representative elementary volume in undrained conditions; e) homogeneous pore pressure within the porous space which amounts to consider no dispersion induced by squirt and/or inertial flow (Dvorkin et al., 1995) and f) no chemical interaction between the fluid and the rock frame.

Under these assumptions, Biot-Gassmann's equation relates the bulk modulus measured in undrained condition $K_{u}$ to the drained bulk modulus $K_{d}$, the solid matrix bulk modulus $K_{s}$, the fluid bulk modulus $K_{f l}$ and the porosity $\phi_{o}$, while the shear modulus $G$ is independent of saturating fluid: 


$$
K_{u}=K_{d}\left[1+\frac{\left(1-\frac{K_{d}}{K_{s}}\right)^{2}}{\left(1-\phi_{o}\right) \frac{K_{d}}{K_{s}}-\left(\frac{K_{d}}{K_{s}}\right)^{2}+\phi_{o} \frac{K_{d}}{K_{f l}}}\right]
$$

Figure 4 plots the $\mathrm{P}$ and $\mathrm{S}$-wave phase velocities measured on the brine-saturated samples as a function of porosity. The measurements have been performed at a differential pressure of $25 \mathrm{MPa}$ for F1 samples and $20 \mathrm{MPa}$ for F2 samples. Both P- and S-wave velocities follow an overall decreasing trend with higher velocity values recorded for F2 samples. This different behavior is most likely related to their higher dolomite content and cannot be explained only by their microporosity level (Figure 5) as proposed by Eberli et al. (2003).

First break velocities are systematically larger than phase velocities as illustrated in Figure 6 for brine-saturated measurements. This deviation can be related to the intrinsic heterogeneity of the studied sample (Dubos-Sallée et al., 2016). The higher deviations observed for F1 samples (up to $11 \%$ for P-wave velocities and $6 \%$ for S-wave velocities) are consistent with their larger pores and grains approaching the centimeter-scale wavelength (Figure 7). The difference is particularly noticeable when the measurements are reported in a $V_{p} / V_{s}$ versus Pwave impedance $\left(I_{P}=\rho V_{P}\right)$ cross-plot commonly used as a rock physics template (RPT) to analyze acoustic velocity behavior (Avseth et al., 2005; Xu and Payne, 2009; Zhao et al., 2013). Phase velocity measurements are all the more recommended as they reveal a behavior closer to the one observed at low frequency (Cadoret et al., 1995).

The very low permeability of samples F2-2 and F2-4 has complicated the fluid substitution process. The whole fluid sequence could be achieved for sample F2-2 with the drawback of longer test duration and higher dispersion of the measured saturated bulk moduli 
which nonetheless remain within the measurement error. The flushing of ethylene-glycol with methanol has proven impossible for sample F2-4 and the test was stopped.

The saturated bulk modulus $\mathrm{K}_{\text {sat }}$ and the shear modulus $\mathrm{G}_{\text {sat }}$ are computed from the Pwave velocity $V_{P}$ and S-wave velocity $V_{S}$ measured for the different saturating fluids:

$$
\begin{aligned}
& \mathrm{K}_{\text {sat }}=\rho\left(V_{P}^{2}-\frac{4}{3} V_{S}^{2}\right) \\
& \mathrm{G}_{s a t}=\rho V_{S}^{2}
\end{aligned}
$$

where $\rho$ is the fluid-saturated rock density. Both phase and first break measurements are used to derive two sets of elastic moduli denoted hereafter with the suffixes PH and FB. Taking into account the $2 \%$ error associated to velocity measurements, equations (8) and (9) lead to errors on $\mathrm{K}_{\text {sat }}$ and $\mathrm{G}_{\text {sat }}$ respectively below $9 \%$ and $5 \%$. As fluids have no time to escape from the pores at ultrasonic frequencies, the saturated elastic moduli obtained for the five liquids used in the fluid substitution process are considered as undrained moduli.

Figure 9 compares the evolution of the measured saturated bulk and shear moduli as a function of the bulk modulus of the saturating fluid for two representative samples of similar porosity level. The points at nearly zero fluid bulk modulus correspond to the bulk and shear moduli measured on the dry samples before the brine saturation. Measurements performed at room dry conditions could be biased by capillary effects (Rasolofosaon and Zinszner, 2003). The deviation between $\phi_{N M R}$ than $\phi_{W e i g h t}$ shows that our samples present a few percent residual saturation after drying sufficient to minimize capillary effects. The elastic moduli deduced from the first break velocity measurements are more scattered and systematically higher than the 
elastic moduli deduced from the phase velocity measurement. The deviation is particularly significant for the bulk modulus of F1 samples.

The measured shear moduli do not vary with the saturating fluid thus indicating no significant shear weakening or strengthening upon brine saturation (Adam et al., 2006; Verwer et al., 2010). The shear modulus of each studied sample is finally given by the mean value obtained for the five saturating liquids.

The saturated bulk modulus increases with the fluid bulk modulus as expected from BiotGassmann's equation. The five sets of $\left(K_{f l}, K_{\text {sat }}\right)$ measurements associated to each saturating liquid are used to fit the two unknowns of Equation (7), namely the drained bulk modulus $K_{d}$ and the solid matrix bulk modulus $K_{s}$. As at least part of the residual brine observed after drying is likely to have remained in place during the miscible fluid replacement, the porosity value considered in the calculations is $\phi_{W e i g h t}$. The inverse analysis of $K_{d}$ and $K_{s}$ has been performed using the least squares method and Excel solver. The errors on the computed drained bulk modulus and solid matrix bulk modulus are estimated at around respectively $9 \%$ and $20 \%$ (Bemer et al., 2016).

Table 6 gives the drained bulk modulus, shear modulus and solid matrix bulk modulus determined for each sample from the phase and first break velocity measurements. First break velocities lead to drained elastic moduli significantly higher than the ones derived from phase velocities: drained bulk moduli are overestimated by $31 \%$ on average for F1 samples and $12 \%$ for F2 samples, while shear moduli are overestimated by $8 \%$ on average for F1 samples and $4 \%$ for F2 samples. Figure 10 and Figure 11 illustrate how well Biot-Gassmann's equation reproduces the evolution of the measured saturated bulk as a function of the fluid bulk modulus 
for the phase velocity measurements. The points marked in white correspond to measurements performed during the reverse flushing by ethanol then brine after heptane-saturated measurements. Except for sample F2-2 which shows some scattering, the obtained results confirmed the perfect reversibility of the fluid substitution process.

Several quality checks of the obtained results can be made. First, the derived phase and first break drained bulk modulus and shear modulus are mostly consistent with the corresponding dry measurements, which confirms the absence of both significant capillary effects and chemical interaction of the saturating fluids and the rock frame. Dry measurements being unaffected by dispersion effects associated to squirt and/or inertial flows, the consistency of dry and drained elastic moduli indicates that the saturated elastic moduli corresponds actually to undrained moduli and not unrelaxed moduli (Pimienta et al., 2015). As no cracks have been observed on thin sections and microscanner images, no squirt-flow effects are expected (Adelinet et al., 2011). The results however confirmed that no specific dispersion was induced by diffusive coupling between the micropores and the macropores of the studied samples (Borgomano et al., 2017). Sample F2-2 which is associated to lower petrophysical properties is the only sample to show a computed drained bulk modulus slightly higher than the measured dry modulus for both phase and first break velocity measurements.

Second, the phase-derived solid matrix bulk moduli are consistent with the mineral forming the continuous skeleton of the samples: calcite for Family 1 and dolomite for Family 2, these minerals being characterized respectively by a bulk modulus of $76.8 \mathrm{GPa}$ and $94.9 \mathrm{GPa}$ (Mavko et al., 1998). The deviations are below 10\%, except for sample F1-21 which shows a solid matrix bulk modulus closer to the bulk modulus of dolomite but remaining consistent with 
calcite one if we take into account the measurement error of $20 \%$. The first-break derived solid matrix bulk moduli of Family 2 are more scattered but still consistent with the phase-derived ones and the expected dolomite value. However, for Family 1, the first-break measurements lead to solid matrix bulk moduli more scattered and significantly higher than the phase-derived ones, thus losing the overall consistency with calcite bulk modulus. This result confirms the higher reliability of phase velocity measurements (Rasolofosaon and Zinszner, 2012).

\section{DISCUSSION: LIMITATIONS OF BIOT-GASSMANN'S EQUATION}

Our results show that Biot-Gassmann's equation is fully satisfied by the studied samples when velocity measurements are obtained through the phase spectral ratio method which minimizes scattering effects associated to carbonate heterogeneity. The fluid substitution method moreover allows the characterization of non-monomineralic samples without any assumption on the solid matrix bulk modulus which is a direct output of the experiment. Dry measurements are used as control points and do not impact the determination of the drained elastic moduli.

If other samples show weakening upon brine saturation, another fluid substitution sequence could be used: heptane, ethanol, mixture of $60 \%$ w ethanol and $40 \%$ w ethylene glycol $\left(K_{f l}=2.11 \mathrm{GPa}\right)$, ethylene glycol, brine. This alternative fluid sequence covers the same range of fluid bulk moduli and keeps the saturation with brine required by the NMR analysis for the last step. The same approach could then be followed to check the applicability of BiotGassmann's equation on the first four liquids and derive consistent values for the drained elastic moduli and the solid matrix bulk modulus. 
Dispersion phenomena remain the only issue. If present, they could be identified through the followed experimental methodology, but would prevent the use of Biot-Gassmann's equation to model the fluid substitution process. The saturated elastic moduli measured for different liquids could then nonetheless be useful to sustain an effective medium modeling approach able to take into account non-homogeneous pore pressures (Adelinet et al., 2011).

The interpolation of the obtained experimental results to predict the petroacoustic response of new samples is however prevented by the absence of a direct relationship between the measured drained elastic moduli and the sample porosity (Figure 12). Drained elastic moduli of both F1 and F2 samples follow an overall decreasing trend as a function of porosity.

Dolomitic samples from Family 2 are stiffer than samples from Family 1 showing the importance of taking the mineralogy into account to model the observed response. The scattering of the elastic moduli around the two mean trends could result from variations in both the mineral contents and microporosity fractions of the samples, thus preventing the simple definition of empirical laws.

The upscaling of the obtained results at the log and the site scales would moreover require integrating the heterogeneity distribution resulting from the sedimentological and diagenetic history of the studied carbonate formations. An effective medium modeling approach based on a comprehensive petrographic characterization has thus been implemented and is presented in a companion paper (Adelinet et al., 2018).

\section{CONCLUSION}


We have proposed an experimental approach allowing a consistent checking of the validity of Biot-Gassmann's equation for a given carbonate formation without referring to lesscontrolled dry measurements and without any assumption on the solid matrix bulk modulus. The obtained results moreover permit the direct identification of any weakening or dispersion effects. The key points of our approach lie in the fluid substitution process followed during the petroacoustic characterization and the use of phase rather than first break velocity measurements to reduce scattering effects. The results obtained on two different carbonate formations show that fluid substitution in the studied samples is well reproduced by Biot-Gassmann's equation and permit to derive consistent drained elastic moduli characterizing the rock frame.

However, the relationship between the derived drained elastic moduli and the porosity is still not direct and involves other microstructure parameters. This issue could be tackle through an effective medium modeling approach. The implemented experimental workflow provides the consistent elastic properties and microstructural information required to constrain the definition of representative microstructure models able to reproduce the petroacoustic signature of carbonate rocks. 
Geophysics

\section{REFERENCES}

Adam, L., Batzle, M., Brevik, I., 2006, Gassmann's fluid substitution and shear modulus variability in carbonates at laboratory seismic and ultrasonic frequencies: Geophysics, 71(6), 173-183.

Adam, L. and Batzle, M., 2008, Elastic properties of carbonates from laboratory measurements at seismic and ultrasonic frequencies: The Leading Edge, 27, 1026-1032.

Adelinet, M., Fortin, J., Guéguen, Y., 2011, Dispersion of elastic moduli in a porouscracked rock: Theoretical predictions for squirt-flow: Tectonophysics, 503, 173-181.

Adelinet, M., Bemer, E. and Hamon, Y., 2018, Effective medium modeling of the diagenesis impact on the petroacoustic properties of carbonate rocks: Geophysics, this issue.

Anselmetti, F.S. and Eberli, G.P., 1993, Controls on Sonic Velocity in Carbonates: PAGEOPH, 141, 287-323.

Assefa, S., McCann, C. and Sothcott, J., 2003, Velocities of compressional and shear waves in limestones: Geophysical Prospecting, 51, 1-13.

Avseth, P., Mukerji, T. and Mavko, G., 2005, Quantitative seismic interpretation: Applying rock physics tools to reduce interpretation risk: Cambridge University Press.

Baechle, G.T., Weger, R.J., Eberli, G.P., Massaferro, J.L., and Sun, Y.F., 2005, Changes of shear moduli in carbonate rocks: Implication for Gassmann applicability: The Leading Edge, 24(5), 507-510. 
Baechle, G.T., Colpaert, A., Eberli, G.P., Weger, R.J., 2008, Effects of microporosity on sonic velocity in carbonate rocks: The Leading Edge, 27(8), 1012-1018.

Bemer, E., Boutéca, M., Vincké, O., Hoteit, N. and Ozanam, O., 2001, Poromechanics: From Linear to Nonlinear Poroelasticity and Poroviscoelasticity: Oil \& Gas Science and Technology - Rev. IFP, 56 (6), 531-544.

Bemer, E., Nguyen, M.T., Dautriat, J., Adelinet, M., Fleury, M. and Youssef, S., 2016, Impact of chemical alteration on the poromechanical properties of carbonate rocks: Geophysical Prospecting, 64, 810-827.

Borgomano, J., Pimienta, L., Fortin, J. and Guéguen, Y., 2017, Dispersion and attenuation measurements of the elastic moduli of a dual-porosity limestone: Journal of Geophysical Research: Solid Earth, 122(4), 2690-2711.

Brigaud, B., Vincent, B., Durlet, C., Deconinck, J.-F., Blanc, P. and Trouiller, A., 2010, Acoustic properties of ancient shallow-marine carbonates: effects of depositional environments and diagenetic processes (Middle Jurassic, Paris Basin, France): Journal of Sedimentary Research, 2010, 80, 791-807.

Brosse, E., Fabriol, H., Fleury, M., Grataloup S. and Lombard J.M., 2010, $\mathrm{CO}_{2}$ Storage in the Struggle against Climate Change: Oil \& Gas Science and Technology - Rev. IFP, 65(3), 369373. 
Geophysics

Cadoret, T., Marion, D. and Zinszner, B., 1995, Influence of frequency and fluid distribution on elastic wave velocities in partially saturated limestones: Journal of Geophysical Research, 100(B6), 9789-9803.

Dennis, B., Akbar, M. and Petricola, M., 2003, Intrinsic potential: Middle East and Asia Reservoir Review, 4, 2-21.

Dvorkin, J., Mavko, G. and Nur, A., 1995, Squirt flow in fully saturated rocks: Geophysics 60(1), 97-107.

Dubos-Sallée, N., Rasolofosaon, P.N.J., Etienne, G., Poitrineau, V., Bemer, E., 2016, Link between Systematic Deviation between First-break Velocity \& Phase Velocity and Heterogeneities in Rocks: Proceedings of the $78^{\text {th }}$ EAGE Conference \& Exhibition 2016 Vienna, Austria, 30 May - 2 June 2016.

Eberli, G.P., Baechle, T., Anselmetti, F.S. and Incze, M.L., 2003, Factors controlling elastic properties in carbonate sediments and rocks: The Leading Edge, 22(7), 654-660.

Fabricius, I.L., Bächle, G.T. and Eberli, G.P., 2010, Elastic moduli of dry and watersaturated carbonates - Effect of depositional texture, porosity, and permeability: Geophysics, 75(3), N65-N78.

Fleury, M., Soualem, J., 2009, Quantitative analysis of diffusional pore coupling from $\mathrm{T}_{2}$ store-T, NMR experiments: J. Coll. Inter. Sciences, 336(1), 350-359.

Green, R.T., Bertetti, F.P. and Miller, M.S., 2014, Focused groundwater flow in a carbonate aquifer in a semi-arid environment: Journal of Hydrology, 517, 284-297. 
Geophysics

Han, D. and Batzle, M.L., 2004, Gassmann's equation and fluid-saturation effects on seismic velocities: Geophysics, 69(2), 398-405.

Kenter, J.A.M., Podladchikov, F.F., Reinders, M., Van der Gaast, S.J., Fouke, B.W. and Sonnenfled, M.D., 1997a, Parameters controlling sonic velocities in a mixed carbonatesiliciclastics Permian shelf-margin (upper San Andres formation, Last Chance Canyon, New Mexico): Geophysics, 62(2), 505-520.

Kenter, J.A.M., Fouke, B.W. and Reinders, M., 1997b, Effects of differential cementation on the sonic velocities of upper cretaceous skeletal grainstones (Southeastern Netherlands): Journal of Sedimentary Research, 67(1), 178-185.

Lenormand, R., 2003, Interpretation of mercury injection curves to derive pore size distribution: Symposium of the Society of Core Analysts, SCA2003-52.

Matonti, C., Guglielmi, Y., Viseur, S., Bruna, P.O., Borgomano, J., Dahl, C. and.Marié, L., 2015, Heterogeneities and diagenetic control on the spatial distribution of carbonate rocks acoustic properties at the outcrop scale: Tectonophysics, 638, 94-111.

Mavko, G., Mukerji, T. and Dvorkin, J., 1998, The Rock Physics handbook: Tools for seismic analysis in porous media: Cambridge University Press.

Parra, J.O., Hackert, C.L., Bennett, M., Collier, H.A., 2003, Permeability and porosity images based on NMR, sonic and seismic reflectivity: application to a carbonate aquifer: The Leading Edge, 22(11), 1102-1108. 
Geophysics

Pimienta, L., Fortin, J. and Gueguen, Y., 2015, Bulk modulus dispersion and attenuation in sandstones: Geophysics, 80(2), D111-D127.

Rasolofosaon, P.N.J., Lucet, N. and Zinszner, B., 2008: Petroacoustic of carbonate rocks: The Leading Edge, 27(8), 1034-1039.

Rasolofosaon, P.N.J. and Zinszner, B., 2003, Petroacoustic Characterization of Reservoir Rocks For Seismic Monitoring Studies - Laboratory Measurement of Hertz and Gassmann Parameters: Oil \& Gas Science and Technology - Rev. IFP, 58 (6), 615-635.

Rasolofosaon, P.N.J. and Zinszner, B., 2012, Experimental verification of the petroelastic model in the laboratory: fluid substitution and pressure effects: Oil \& Gas Science and Technology - Rev. IFP, 67(2), 303-318.

Regnet, J. B., Robion, P., David, C., Fortin, J., Brigaud, B. and Yven, B., 2015, Acoustic and reservoir properties of microporous carbonate rocks: Implication of micrite particle size and morphology: Journal of Geophysical Research: Solid Earth, 120(2), 790-811.

Rietvield, H.M., 1969, A profile refinement method for nuclear and magnetic structures: Journal of Applied Crystallography, 2, 65-71.

Verwer, K., Braaksma, H. .and Kenter, J.A.M., 2008, Acoustic properties of carbonates: Effects of rock texture and implications for fluid substitution: Geophysics, 73(2), B51-B65.

Verwer, K., Eberli, G., Baechle, G. and Weger, R., 2010, Effect of carbonate pore structure on dynamic shear moduli: Geophysics, 75(1), E1-E8. 
Geophysics

Vincent, B., Fleury, M., Santerre, Y., Brigaud, B., 2011, NMR relaxation of neritic carbonates: an integrated petrophysical and petrographical approach: Journal of Applied Geophysics, 74, 38-58.

Weger, R.J., Eberli, G.P., Baechle, G.T., Massaferro, J.L. and Sun, Y.-F., 2009 Quantification of pore structure and its effect on sonic velocity and permeability in carbonates: AAPG Bulletin, 93(10), 1297-1317.

Yan, F. and Han, D., 2016, Effect of pore geometry on Gassmann's fluid substitution: Geophysical prospecting, 2016, 64, 1575-1587.

Xu, S. and Payne, M. A., 2009, Modeling elastic properties in carbonate rocks: The Leading Edge, 28(1), 66-74.

Zhao, L., Nasser, M. and Han, D., 2013, Quantitative geophysical pore-type characterization and its geological implication in carbonate reservoirs: Geophysical Prospecting, 61, 827-841. 


\section{LIST OF FIGURES}

Figure 1. Experimental characterization workflow. 30 Figure 2. Illustration of image subtraction. From left to right: 2D slice of dry sample F1-13; corresponding KI-saturated 2D slice; subtraction result showing the macropores in yellow, the microporous phase in purple and the solid phase in black. 30 Figure 3. Normalized NMR and MICP pore size distributions. The vertical thick lines indicate the positions of the $200 \mathrm{~ms}$ and $2 \mu \mathrm{m}$ cut-offs. 31 Figure 4. P-wave (VP) and S-wave (VS) phase velocities measured on the brine-saturated samples versus porosity ( $\phi W e i g h t)$.

Figure 5. P-wave (VP) and S-wave (VS) phase velocities measured on the brine-saturated samples versus microporosity.

Figure 6. Comparison of first break and phase velocities measured on the brine-saturated samples.

Figure 7. Transmitted light plane-polarized photomicrographs of A) Family F1 sample showing macropores ( $\Phi$ ), calcite mesoclots (Mc.) and dolomite cement (Do.) and B) Family F2 sample showing dolomitized matrix, syntaxial cement (white arrow) and fabricpreserving replacement of aragonitic allochems (black arrow). 33

Figure 8. Illustration of the potential impact on rock typing of the deviation between first

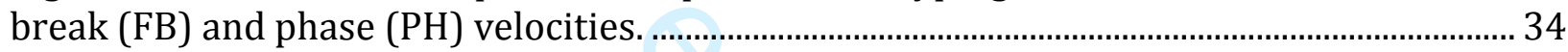

Figure 9. Saturated elastic moduli versus fluid bulk modulus.................................................. 34 Figure 10. Petroacoustic signature of fluid substitution for F1 samples. ................................ 35 Figure 11. Petroacoustic signature of fluid substitution for F2 samples. Same captions as in Figure 10. 36

Figure 12. Drained elastic moduli as a function of porosity 


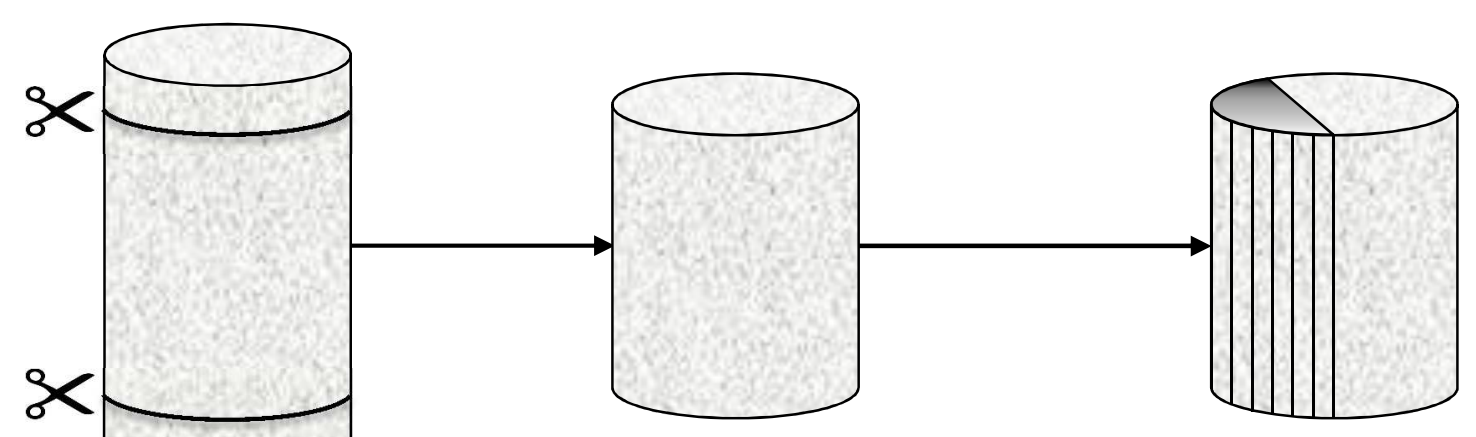

\section{Selection of the sample most} homogeneous part through CT-scanner observation

\author{
Non-destructive testing \\ sequence: \\ - Petroacoustic testing \\ - Porosity measurement \\ - NMR analysis \\ - Permeability measurement
}

\section{Microstructure characterization:}

- Vertical thin section (hatched area)

- XRD analysis

- Mercury Injection Capillary Pressure (MICP)

- Microscanner imaging

Figure 1. Experimental characterization workflow.
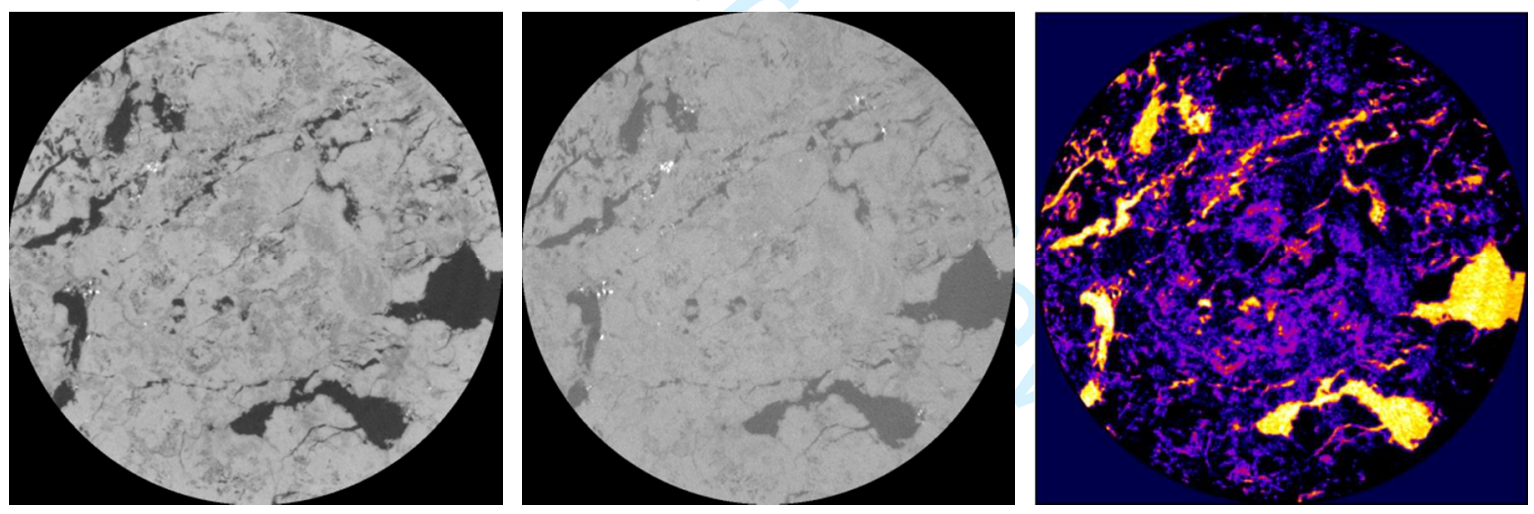

Figure 2. Illustration of image subtraction. From left to right: 2D slice of dry sample F1-13; corresponding KI-saturated 2D slice; subtraction result showing the macropores in yellow, the microporous phase in purple and the solid phase in black. 
Geophysics
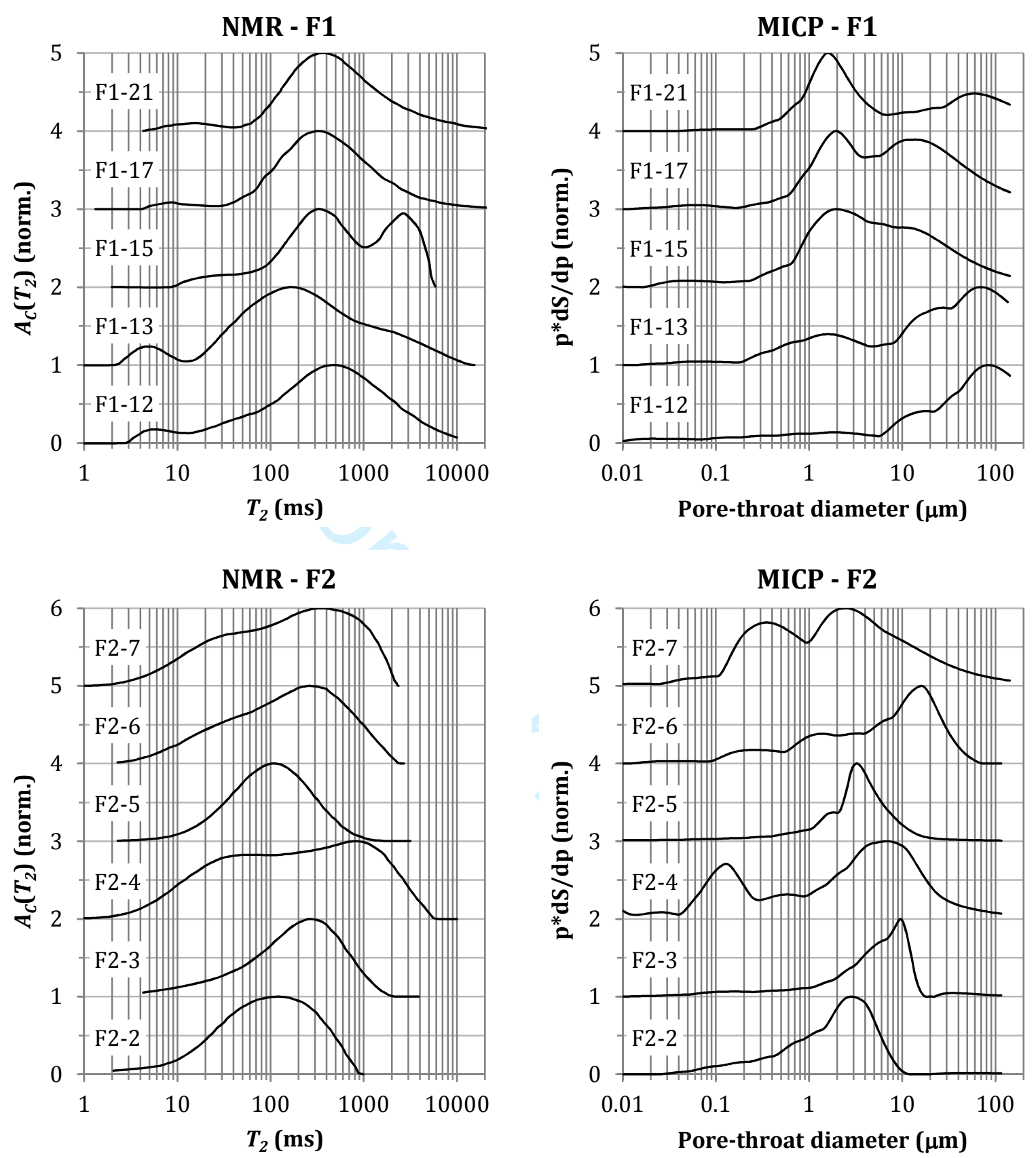

Figure 3. Normalized NMR and MICP pore size distributions. The vertical thick lines indicate the positions of the $200 \mathrm{~ms}$ and $2 \mu \mathrm{m}$ cut-offs. 
Geophysics

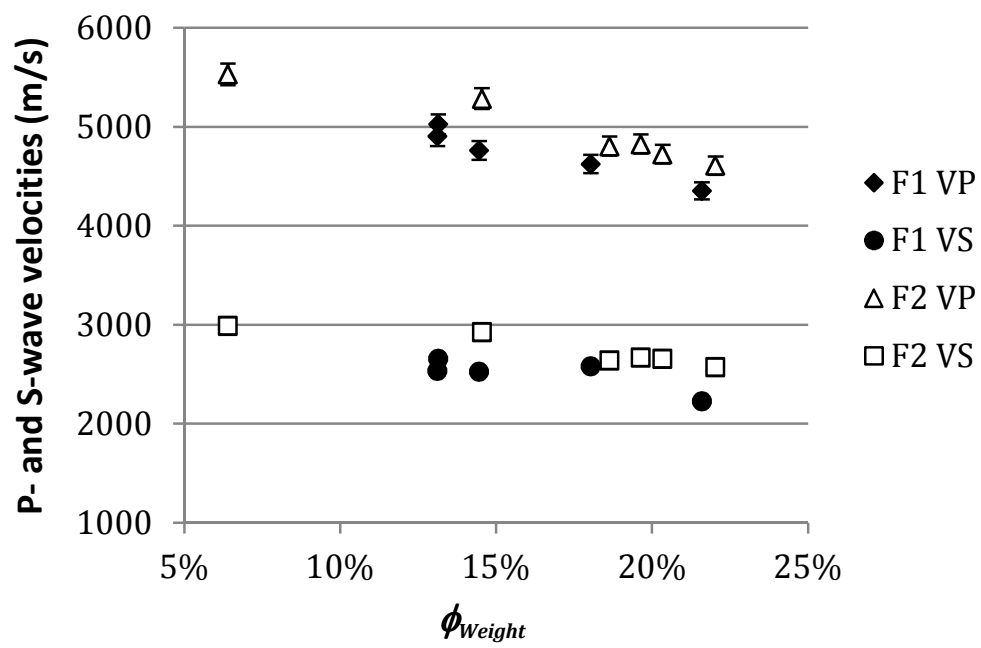

Figure 4. P-wave $\left(V_{P}\right)$ and $\mathrm{S}$-wave $\left(V_{S}\right)$ phase velocities measured on the brine-saturated samples versus porosity $\left(\phi_{\text {Weight }}\right)$.

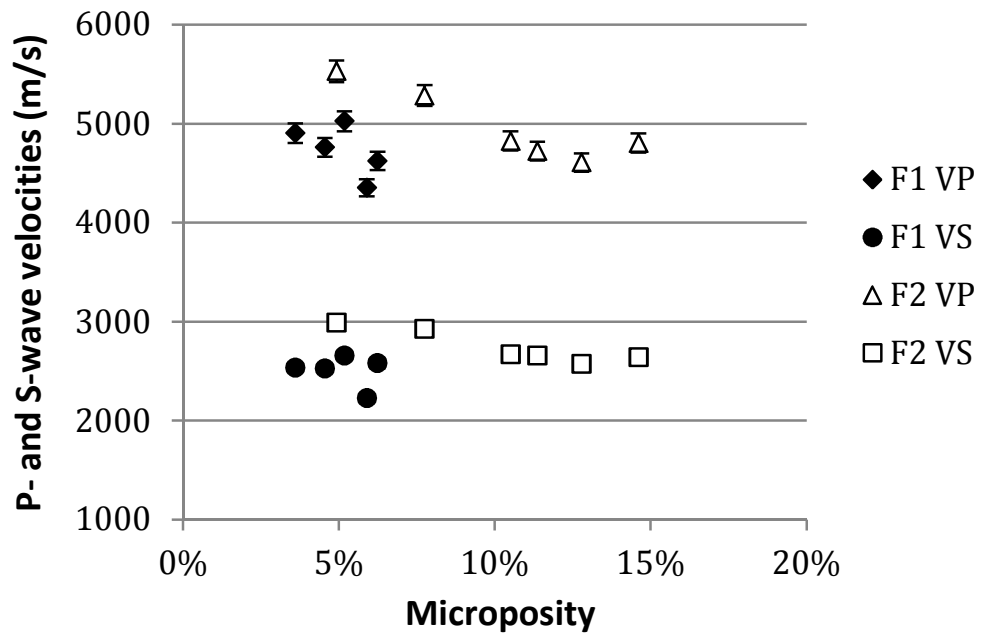

Figure 5. P-wave $\left(V_{P}\right)$ and $\mathrm{S}$-wave $\left(V_{S}\right)$ phase velocities measured on the brine-saturated samples versus microporosity. 
Geophysics

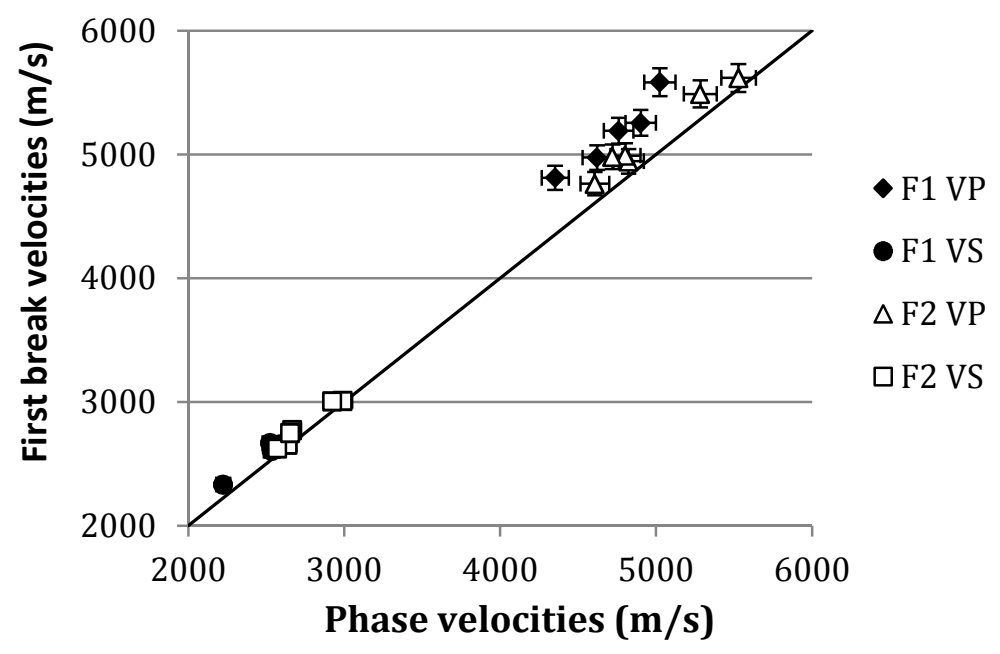

Figure 6. Comparison of first break and phase velocities measured on the brine-saturated samples.
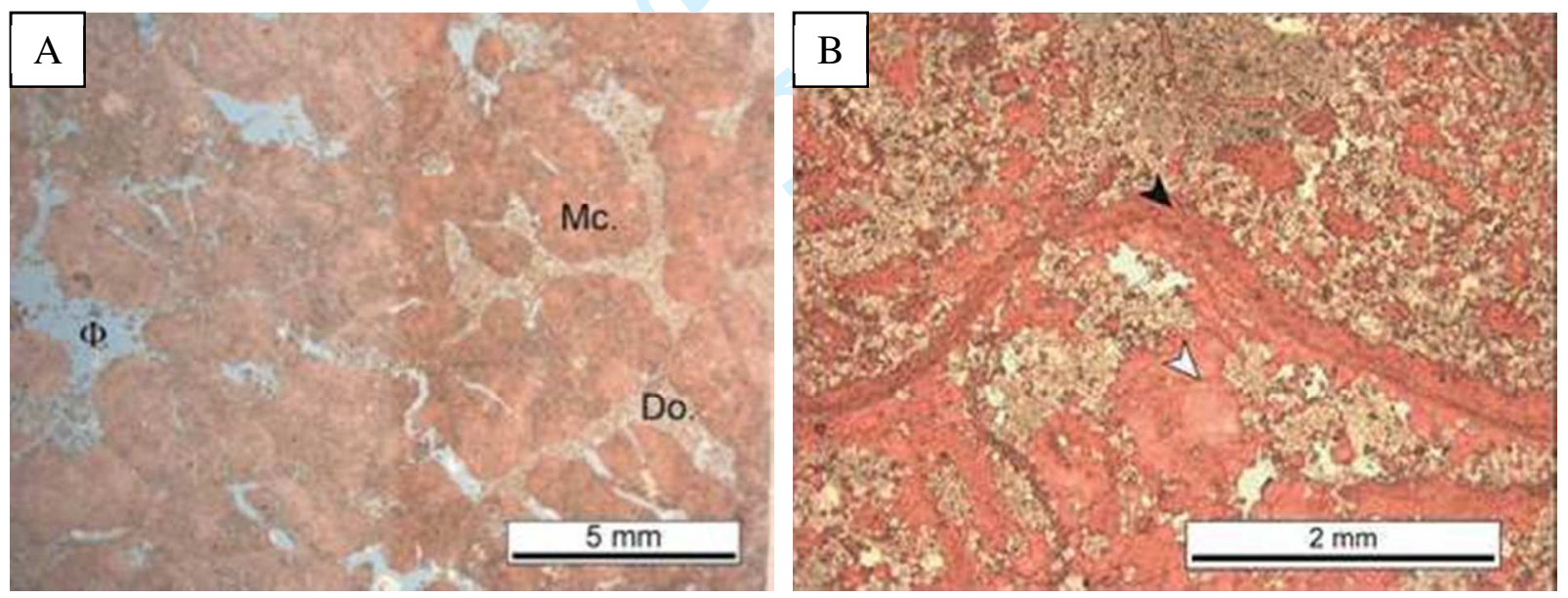

Figure 7. Transmitted light plane-polarized photomicrographs of A) Family F1 sample showing macropores $(\Phi)$, calcite mesoclots (Mc.) and dolomite cement (Do.) and B) Family F2 sample showing dolomitized matrix, syntaxial cement (white arrow) and fabric-preserving replacement of aragonitic allochems (black arrow). 
Geophysics

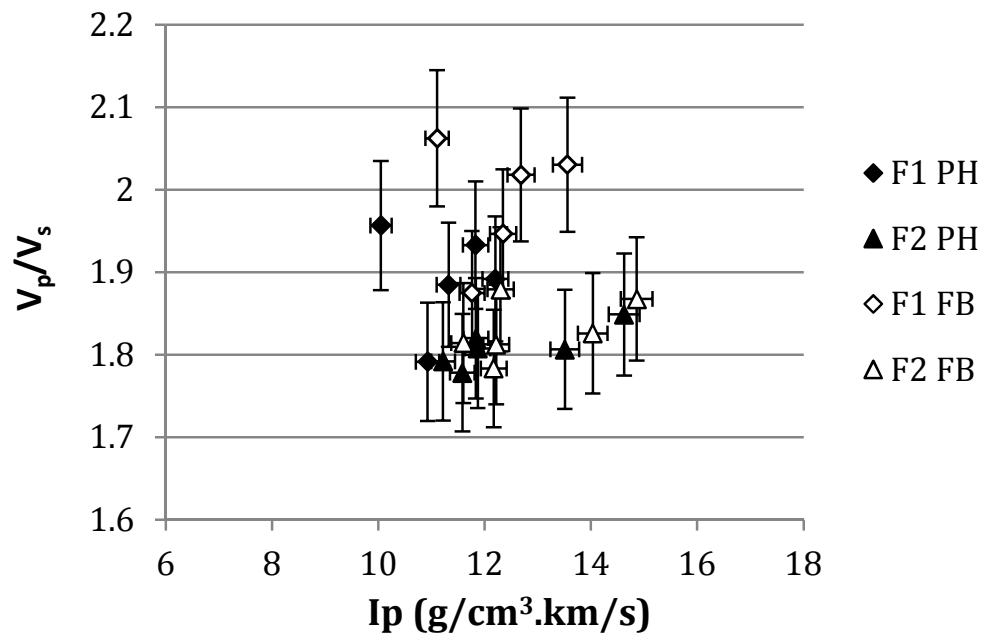

Figure 8. Illustration of the potential impact on rock typing of the deviation between first break (FB) and phase $(\mathrm{PH})$ velocities.
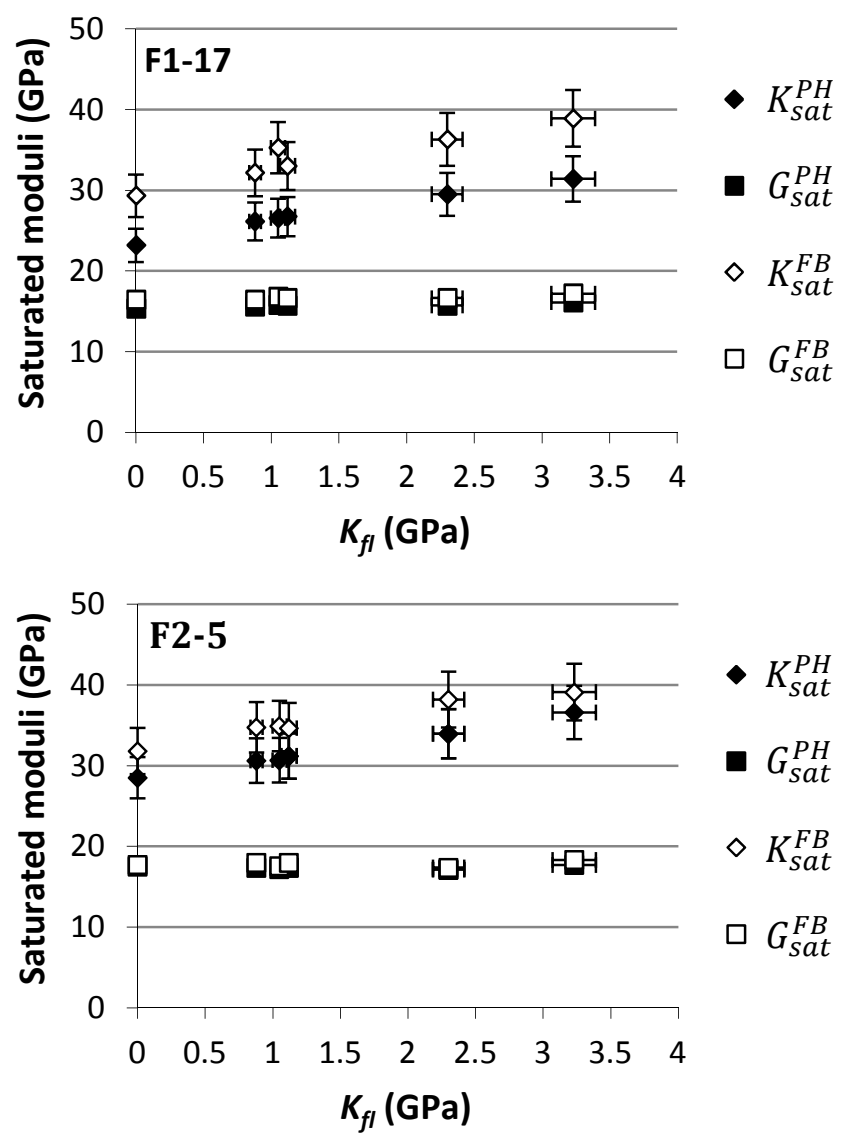

Figure 9. Saturated elastic moduli versus fluid bulk modulus. 

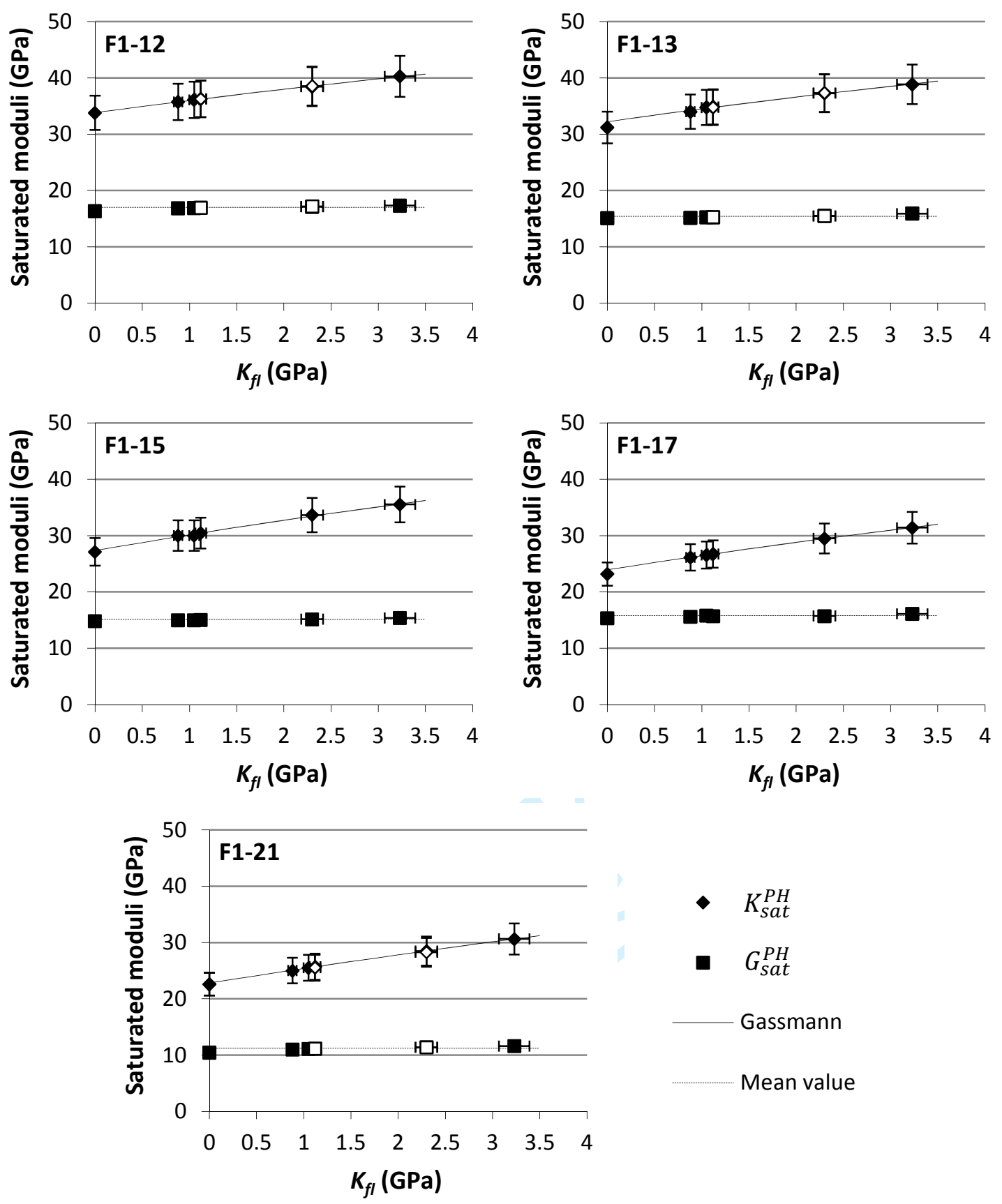

Figure 10. Petroacoustic signature of fluid substitution for F1 samples. 

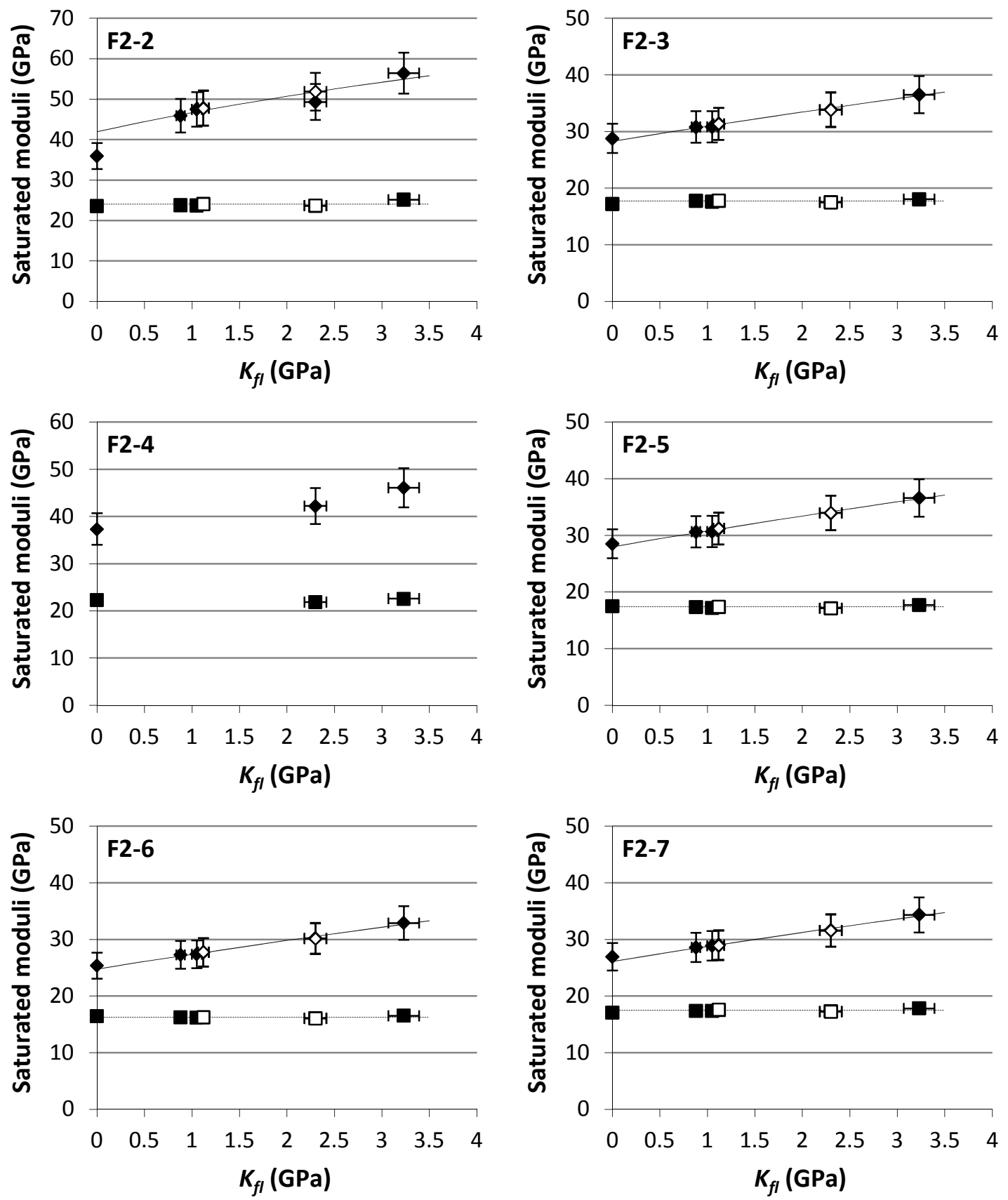

Figure 11. Petroacoustic signature of fluid substitution for F2 samples. Same captions as in Figure 10. 
Geophysics

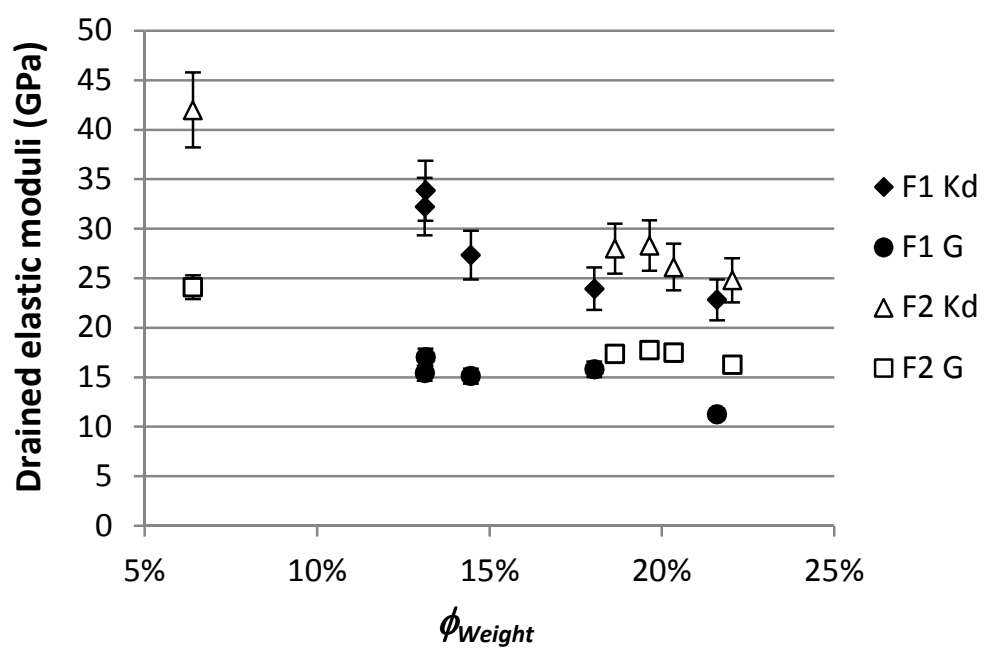

Figure 12. Drained elastic moduli as a function of porosity. 


\section{LIST OF TABLES}

Table 1. Physical properties of the fluids used in the substitution process, listed according to their miscibility with the previous fluid. 38

Table 2. Different classes of microstructure information............................................................. 38

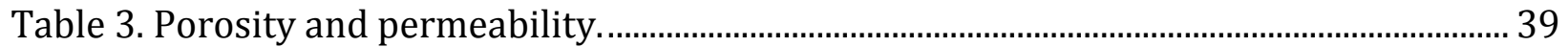

Table 4. Mineral content deduced from XRD analysis............................................................... 40

Table 5. Microporosity and macroporosity fractions deduced from NMR, MICP and

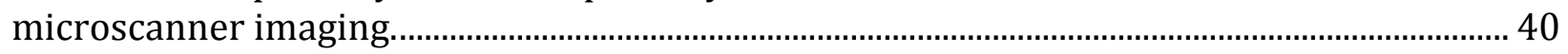

Table 6. Petroacoustic properties deduced from first break and phase velocity

measurements.

Table 1. Physical properties of the fluids used in the substitution process, listed according to their miscibility with the previous fluid.

\begin{tabular}{cccc} 
Fluid & $\begin{array}{c}\text { Bulk modulus } \\
(\mathbf{G P a})\end{array}$ & $\begin{array}{c}\text { Density } \\
\left(\mathbf{g} / \mathbf{c m}^{\mathbf{3}}\right)\end{array}$ & $\begin{array}{c}\text { Viscosity } \\
(\mathbf{c P})\end{array}$ \\
\hline Brine $(\mathrm{NaCl} 25 \mathrm{~g} / \mathrm{l})$ & 2.30 & 1.019 & 1 \\
\hline Ethylene glycol & 3.23 & 1.1135 & 19 \\
\hline Methanol & 1.05 & 0.791 & 0.6 \\
\hline Ethanol & 1.12 & 0.789 & 1.2 \\
\hline Heptane & 0.88 & 0.684 & 0.4 \\
\hline
\end{tabular}

Table 2. Different classes of microstructure information.

\begin{tabular}{|c|c|c|c|}
\hline Method & $\begin{array}{l}\text { Analyzed } \\
\text { material }\end{array}$ & Provided information & Limitations \\
\hline $\begin{array}{l}\text { Petrographic } \\
\text { analysis }\end{array}$ & $\begin{array}{l}\text { Thin } \\
\text { section }\end{array}$ & $\begin{array}{l}\text { 2D structural information } \\
\text { - Mineral content and } \\
\text { distribution between grain } \\
\text { and cement phases } \\
\text { - Macroporosity } \\
\text { - Location of microporosity }\end{array}$ & $\begin{array}{l}\text { Resolution around 25- } \\
30 \mu \mathrm{m}\end{array}$ \\
\hline Microscanner & $8-\mathrm{mm}$ & $3 D$ structural information & - Resolution of $8 \mu \mathrm{m}$ \\
\hline
\end{tabular}




\begin{tabular}{|c|c|c|c|}
\hline imaging & $\begin{array}{c}\text { diameter } \\
\text { sub-sample }\end{array}$ & $\begin{array}{l}\text { - Porosity deduced from the } \\
\text { density difference between } \\
\text { KI-saturated and dry samples } \\
\text { - Macroporosity } \\
\text { - Microporous phase fraction } \\
\text { - Mineral composition of non- } \\
\text { microporous phases }\end{array}$ & $\begin{array}{l}\text { - Imaging artifacts } \\
\text { - Mineralogy of the } \\
\text { microporous phase } \\
\text { unknown } \\
\text { Assumptions on the grey- } \\
\text { level thresholds between } \\
\text { the various mineral phases }\end{array}$ \\
\hline XRD & Powder & $\begin{array}{l}\text { Mineral content } \\
\text { Higher precision than thin } \\
\text { section analysis }\end{array}$ & $\begin{array}{l}\text { No link with the structural } \\
\text { repartition of the } \\
\text { identified mineral phases }\end{array}$ \\
\hline
\end{tabular}

\section{Petrophysical information}

- Porosity deduced from the measured brine-saturated pore volume

- Pore size distribution in terms of pore volume over surface ratio

- Proportion of microporosity and macroporosity (200 ms $T_{2}$ threshold)
No link with the structural repartition of the micropores and $T_{2}$ distribution possibly impacted by diffusive coupling between micropores and macropores

\section{Petrophysical information}

\section{MICP}

(mercury

injection

capillary

pressure)
- Porosity deduced from the volume of mercury injected

- Pore throat size distribution

- Proportion of microporosity and macroporosity ( $2 \mu \mathrm{m}$ pore throat threshold)
No link with the structural repartition of the micropores and macropores possibly wrongly attributed to the microporous volume if they are accessible only through small pore throats

Table 3. Porosity and permeability.

\begin{tabular}{cccccc} 
Sample & $\boldsymbol{\phi}_{\text {Weight }}$ & $\boldsymbol{\phi}_{\text {NMR }}$ & $\boldsymbol{\phi}_{\text {MICP }}$ & $\boldsymbol{\phi}_{\boldsymbol{C T}}$ & $\boldsymbol{k}(\mathbf{m D})$ \\
\hline F1-12 & $13.1 \%$ & $14.1 \%$ & $11.9 \%$ & $12.3 \%$ & 174 \\
\hline F1-13 & $13.1 \%$ & $15.3 \%$ & $11.1 \%$ & $11.4 \%$ & 380 \\
\hline
\end{tabular}




\begin{tabular}{cccccc}
\hline F1-15 & $14.4 \%$ & $15.1 \%$ & $14.6 \%$ & & 175 \\
\hline F1-17 & $18.0 \%$ & $18.9 \%$ & $18.2 \%$ & $19.9 \%$ & 398 \\
\hline F1-21 & $21.6 \%$ & $21.7 \%$ & $16.9 \%$ & & 0.1 \\
\hline F2-2 & $6.4 \%$ & $6.7 \%$ & $8.2 \%$ & $18.2 \%$ & 5.7 \\
\hline F2-3 & $19.6 \%$ & $20.3 \%$ & $15.2 \%$ & & 0.2 \\
\hline F2-4 & $14.5 \%$ & $15.3 \%$ & $14.4 \%$ & $26.6 \%$ & 4.2 \\
\hline F2-5 & $18.6 \%$ & $19.5 \%$ & $14.8 \%$ & $29.0 \%$ & 1.2 \\
\hline F2-6 & $22.0 \%$ & $22.8 \%$ & $21.2 \%$ & & 3.4 \\
\hline F2-7 & $20.3 \%$ & $21.4 \%$ & $16.0 \%$ & & \\
\hline
\end{tabular}

Table 4. Mineral content deduced from XRD analysis.

\begin{tabular}{ccccc} 
Sample & Sample & Calcite & Dolomite & Silicate \\
\hline F1-12 & 12 & $52.1 \%$ & $36.1 \%$ & $11.8 \%$ \\
\hline F1-13 & 13 & $78.3 \%$ & $19.3 \%$ & $2.4 \%$ \\
\hline F1-15 & 15 & $67.6 \%$ & $25.0 \%$ & $7.4 \%$ \\
\hline F1-17 & 17 & $81.0 \%$ & $12.7 \%$ & $6.3 \%$ \\
\hline F1-21 & 21 & $82.4 \%$ & $13.5 \%$ & $4.1 \%$ \\
\hline F2-2 & 2 & $41.5 \%$ & $56.2 \%$ & $2.3 \%$ \\
\hline F2-3 & 3 & $8.4 \%$ & $88.3 \%$ & $3.4 \%$ \\
\hline F2-4 & 4 & $0.1 \%$ & $96.5 \%$ & $3.4 \%$ \\
\hline F2-5 & 5 & $2.5 \%$ & $93.6 \%$ & $3.9 \%$ \\
\hline F2-6 & 6 & $0.1 \%$ & $95.6 \%$ & $4.3 \%$ \\
\hline F2-7 & 7 & $0.1 \%$ & $95.9 \%$ & $4.0 \%$ \\
\hline
\end{tabular}

Table 5. Microporosity and macroporosity fractions deduced from NMR, MICP and microscanner imaging. 
Geophysics

NMR analysis MICP analysis Microscanner imaging (200 ms threshold $) \quad(2 \mu \mathrm{m}$ threshold $) \quad(8 \mu \mathrm{m}$ resolution $)$

\begin{tabular}{ccccccc}
\hline Sample & $f_{\text {micro }}^{N M R}$ & $f_{\text {Macro }}^{N M R}$ & $f_{\text {micro }}^{\text {MICP }}$ & $f_{\text {Macro }}^{\text {MICP }}$ & $f_{\text {micro }}^{C T}$ & $f_{\text {Macro }}^{C T}$ \\
\hline F1-12 & $39 \%$ & $61 \%$ & $18 \%$ & $82 \%$ & $40 \%$ & $60 \%$ \\
\hline F1-13 & $53 \%$ & $47 \%$ & $21 \%$ & $79 \%$ & $27 \%$ & $73 \%$ \\
\hline F1-15 & $32 \%$ & $69 \%$ & $31 \%$ & $69 \%$ & & \\
\hline F1-17 & $35 \%$ & $65 \%$ & $24 \%$ & $76 \%$ & & \\
\hline F1-21 & $27 \%$ & $73 \%$ & $36 \%$ & $64 \%$ & $35 \%$ & $65 \%$ \\
\hline F2-2 & $77 \%$ & $23 \%$ & $48 \%$ & $52 \%$ & & \\
\hline F2-3 & $54 \%$ & $47 \%$ & $21 \%$ & $79 \%$ & $77 \%$ & $23 \%$ \\
\hline F2-4 & $53 \%$ & $47 \%$ & $43 \%$ & $57 \%$ & & \\
\hline F2-5 & $78 \%$ & $22 \%$ & $26 \%$ & $74 \%$ & $70 \%$ & $30 \%$ \\
\hline F2-6 & $58 \%$ & $42 \%$ & $26 \%$ & $74 \%$ & $59 \%$ & $41 \%$ \\
\hline F2-7 & $56 \%$ & $44 \%$ & $50 \%$ & $50 \%$ & &
\end{tabular}


Table 6. Petroacoustic properties deduced from first break and phase velocity measurements.

\begin{tabular}{ccccccc}
\hline & \multicolumn{2}{c}{ Phase velocity measurements } & \multicolumn{3}{c}{ First break velocity measurements } \\
\hline Sample & $\boldsymbol{K}_{\boldsymbol{d}}^{\boldsymbol{P H}}(\mathbf{G P a})$ & $\boldsymbol{G}^{\boldsymbol{P H}}(\mathbf{G P a})$ & $\boldsymbol{K}_{\boldsymbol{s}}^{\boldsymbol{P H}}(\mathbf{G P a})$ & $\boldsymbol{K}_{\boldsymbol{d}}^{\boldsymbol{F}}(\mathbf{G P a})$ & $\boldsymbol{G}^{\boldsymbol{F} \boldsymbol{B}}(\mathbf{G P a})$ & $\boldsymbol{K}_{\boldsymbol{s}}^{\boldsymbol{F} \boldsymbol{B}}(\mathbf{G P a})$ \\
\hline F1-12 & 33.8 & 17.0 & 74.2 & 46.7 & 18.3 & 96.5 \\
\hline F1-13 & 32.2 & 15.4 & 73.0 & 39.9 & 16.4 & 88.6 \\
\hline F1-15 & 27.3 & 15.1 & 78.6 & 35.7 & 16.8 & 90.2 \\
\hline F1-17 & 23.9 & 15.8 & 76.1 & 30.8 & 16.7 & 102.2 \\
\hline F1-21 & 22.8 & 11.3 & 92.6 & 30.5 & 12.4 & 128.5 \\
\hline F2-2 & 42.0 & 24.1 & 97.5 & 44.9 & 24.1 & 97.8 \\
\hline F2-3 & 28.3 & 17.7 & 104.3 & 30.8 & 18.5 & 103.2 \\
\hline F2-4 & & & & & & \\
\hline F2-5 & 28.0 & 17.4 & 103.7 & 32.6 & 17.8 & 94.4 \\
\hline F2-6 & 24.8 & 16.2 & 104.1 & 28.4 & 17.0 & 85.6 \\
\hline F2-7 & 26.1 & 17.5 & 100.2 & 29.9 & 18.6 & 107.5
\end{tabular}

